\title{
Growth Rate and Chemical Composition of Secondary Metabolite Extracellular Polysaccharide (EPS) in Microalga Porphyridium cruentum
}

\author{
Nurul Mutmainnah ${ }^{1 *}$, Yenny Risjani ${ }^{2}$, Asus Maizar Suryanto Hertika ${ }^{3}$ \\ ${ }^{1}$ Master Program of Aquaculture, Faculty of Fisheries and Marine Sciences, University of Brawijaya, Malang, Indonesia \\ ${ }^{2}$ Central Laboratory of Life Sciences (LSIH), University of Brawijaya, Malang, Indonesia \\ ${ }^{3}$ Department of Water Resources Management, Faculty of Fisheries and Marine Sciences, University of \\ Brawijaya, Malang, Indonesia
}

\begin{abstract}
Porphyridium cruentum microalgae have great potential to be developed as a source of active ingredients in various fields of health. It excretes secondary metabolites in the form of extracellular polysaccharides (EPS), potentially as antibacterial, antihyperglycemic, and immunostimulant components. This study aims to obtain the best culture density of $P$. cruentum, the active component of $P$. cruentum (EPS), and the chemical composition of EPS. The $P$. cruentum was cultivated on $15 \%, 20 \%$ and $25 \%$ culture stock, with an addition of silicate, Fe and vitamins in sterile seawater medium with salinity $35 \%$, $\mathrm{pH} 8$, temperature $25-27^{\circ} \mathrm{C}$, with continuous aeration and 2500 lux continuous 24 hours, for 14 days of culture period. The results of this study indicate differences in growth rates and abundance of microalgae to each culture stock. The $15 \%, 20 \%$ and $25 \%$ culture stocks each showed stationary phase at days $10^{\text {th }}, 12^{\text {th }}$ and $14^{\text {th }}$, with EPS concentrations of $10 \mathrm{ppt}, 12 \mathrm{ppt}$, and $15 \mathrm{ppt}$, respectively. Variation of $P$. cruentum culture showed different EPS results, with a density of $25 \%$ capable of producing the highest EPS extract of $15,000 \mathrm{mg} \cdot \mathrm{L}^{-1}$. The EPS is known to contain glucose and carboxylic acid compounds that can be utilized in the health and industrial fields.
\end{abstract}

Keywords: culture, extracellular polysaccharides, Porphyridium cruentum.

\section{INTRODUCTION}

Porphyridium cruentum is one of the rare, single-celled, colon-free Rhodophyceae classes found in moist, freshwater, and dominant terrains found in marine waters [1,2]. The $P$. cruentum cell is about 4-9 $\mu \mathrm{m}$ in diameter, with cell structure consisting of nucleus, golgi body, mitochondria, chloroplasts, starch, mucus and vesicles. It contains red pigment phycoerythrin which is an additional pigment in the cell, dominant to cover the green color of chlorophyll. The pigment content is affected by the depth of the habitat, the deeper the habitas, phycoerythrin become more dominant, and it decrease in the shallower water. The $P$. cruentum contains chlorophyll a and has no chlorophyll $b$, but it has chlorophyll $\mathrm{d}$. The red pigment $P$. cruentum masks the color of other photosynthetic pigments, so this red pigment becomes the main pigment that plays a role in the reception of light in the process of photosynthesis [1-4].

The $P$. cruentum cell is bound in the mucilago. Mucilago is a compound expressed by a cell constantly forming a capsule, and surrounds a cell, containing a sulfate polysaccharide or

\footnotetext{
* Correspondence address:

Nurul Mutmainnah

Email : nurulmuhtar21@gmail.com

Address : Faculty of Fisheries and Marine Sciences, University of Brawijaya, Veteran Malang, Malang 65145.
}

otherwise known as EPS. EPS is essentially a secondary metabolite of microalgae useful as a protective for microalga cell in the conditions that do not support its life survival. As a source of nutritional reserves in nutritional deficiencies, microalgae cell coatings keep the cells protected from extreme temperature changes. EPS becomes one of the important components in $P$. cruentum function as antioxidant, antibacterial, antiviral, and anti hyperglycemic $[2,5,6]$. In addition $P$. cruentum contains carotenoids which are useful in improving the immune system $[7,8]$.

Porphyridium cruentum has a carbohydrate biomass composition value of $32.1 \%(w / w)$, $34.1 \%$ crude protein. Mineral contents in $100 \mathrm{~g}$ of dried biomass are $\mathrm{Na}(1130 \mathrm{mg}), \mathrm{Mg}(629 \mathrm{mg}), \mathrm{Ca}$ (4960 mg), K (1190 mg), and Zn (373 mg). The fatty acid content is $1.6 \%$ for $16: 0,0.4 \%$ for $18: 2 \dot{\omega} 6,1.3 \%$ to $20: 4 \dot{\omega} 6$, and $1.3 \%$ for $20: 5 \dot{\omega} 6$. The biomass of $P$. cruentum contains pigment in the form of phycoerythrin characteristic of red color. Besides that, the biomass also contains vitamin $\mathrm{K}$, tocopherol and carotene. These microalgae contain active components of phenol, sterols, terpenoids, flavonoids and polysaccharides that can be used as antiviral, antibacterial, antioxidant $[2,9]$.

This microalgae is important to be explored because it has various benefits that can be applied in various fields, especially in medical field. Currently efforts to formulate alternative treat- 
ments are increasingly being made, requiring eco-friendly materials and abundant and accessible availability. One material that can be used as an alternative is to utilize microalgae, among others, the red microalgae $P$. cruentum. Microalgae is easily cultivated and able to grow quickly, in addition to the utilization of this microalga will increase the choice of raw materials that can be utilized in various fields both health and industry.

Efforts to explore the benefits of $P$. cruentum increasingly crowded, but the less of microalgae biomass is limiting the use of space to scale on in vitro only. So that method and modification of treatment to cultivate $P$. cruentum cultivation process must be developed, to obtain the right method to fulfill the needs of $P$. cruentum biomass on a wider scale. The purpose of this study is to obtain the best culture density of $P$. cruentum, the active component of $P$. cruentum (EPS), and the chemical composition of EPS in $P$. cruentum.

\section{MATERIAL AND METHOD}

The method used in this study is an experimental method, which is a deliberate method with certain controlled treatment in a place. This research was conducted at Fish Reproduction Laboratory and Parasitic and Fish Disease Laboratory, Faculty of Fisheries and Marine Sciences, University of Brawijaya, Malang.

\section{Data Collection \\ Cultivation of Porphyridium cruentum}

Porphyridium cruentum microalgae seeds used in this research were obtained from Brackish Water Aquaculture Center (BBAP) Situbondo. The cultivation media using seawater that has been in sterilization by boiling. The tools used were sterilized using chlorine 15 g.L.-1 diluent, after diluted chlorine sprayed sufficiently into a glass jar container of $1.5 \mathrm{~L}$ capacity which has been filled with plain water and allowed to stand for 24 hours. Furthermore, the water is drained and the container is allowed to dry until it is completely dry before the tool is used. Cultivation with the addition of Fe and silicates and vitamins as much as $1 \mathrm{~mL} . \mathrm{L}^{-1}$. The lighting 2500 lux and aeration is continuously with $15 \%$, $20 \%$ and $25 \%$ culture stock $[10,11,12]$. The microalgae cultivation is in laboratory scale that carried out for 7-14 days, and observed the density of microalgae growth daily using hemositometer with the aid of 400x magnification light microscope [13].

\section{Extracellular Polysaccharide Extraction (EPS)}

The EPS extraction process was conducted based on Raposo et al. [14], where fresh $P$. cruentum in culture medium was centrifuged at $10,000 \mathrm{rpm}$ for $20-30 \mathrm{~min}$ at $4^{\circ} \mathrm{C}$. The formed pellets are removed and only take the supernatant containing EPS. The supernatant is placed under a ventilated hotte to obtain a suspension containing EPS. After 3-4 days, the sample is placed in water bath at $80^{\circ} \mathrm{C}$ for 1 hour. Suspensions containing EPS are filtered using simple filter paper and the extraction is refined by precipitation with two variations of cold ethanol volume (as required). After the EPS obtained, previously treated with freeze dryer before and after the dialysis process. The process of dialysis is carried out by resuspending dry EPS in distilled water and the process of dialysis using cellulose membranes. This process is done several times.

\section{EPS Chemical Composition Analysis}

The chemical composition test of EPS by FTIR method is based on Mishra and Jha [15] research. Fourier Transform Infrared (FTIR) in general aims to detect functional groups of certain compounds, so that the compiler compound can be known in a more detail than just phytochemical test. The test was carried out by homogenizing $200 \mathrm{mg}$ of $\mathrm{Kbr}$ as well as $2 \mathrm{mg}$ of EPS powder in the mortar. Samples that have been homogeneous compacted and fed into tensor 37. The test sample is measured at a wavelength of $4000-500 \mathrm{~cm}^{-1}$, resulting in FTIR spectra showing the absorption peaks of the sample wave number. Functional groups are determined by the absorption peaks of expressed wave numbers.

\section{RESULT AND DISCUSSION}

Biomass production of Porphyridium cruentum

The Porphyridium cruentum microalga growth with $15 \%, 20 \%$, and $25 \%$ culture stock density reached peak on $10^{\text {th }}$ day and decreased and stable on day 11 until day 14. Generally microalgae growth through several phases starting with phase lag (adjustment), logarithmic phase (growth), stationary phase (stop growing) and ending with death phase [13]. The abundance of $P$. cruentum which tends to be stable after passing through the stationary phase i.e. on the $8^{\text {th }}$ day, can be caused by continuous aeration and lighting treatment, and the availability of nutrients needed by the microalgae to grow. Until at certain times, the growth will be completely stopped and die, i.e. in the conditions 
where nutrients are no longer available in the growth medium of $P$. cruentum. Through this study, the time occurs at week 5 of culture, without the addition of nutrients, where the aeration and lighting process continues.

The growth of $P$. cruentum is influenced by internal factors such as the quality of microalgae itself. It is also strongly influenced by external factors such as availability of light (2500-3000 lux), temperature $\left(25-27^{\circ} \mathrm{C}\right)$, media quality (sterile), and availability of nutrients (vitamins, Fe, silicate, phosphate and nitrate) $[2,16]$.

There is a difference in the rate of growth in the variation of the microalgae culture stock, which is due to the microalgae cell density itself, as well as the uneven nutritional and lighting requirements that support the variation in growth rate. Prayitno explained that cell culture density affects the growth pattern of microalgae [17], which in high culture stock can shorten the phase of lag (phase of adjustment), and exponen- tial phase increases faster. Denser culture stock conditions cause increasing competition between cells to obtain light and nutrients. Thus in conditions of lack of light, it can disrupt the process of cell division. In addition, if aeration forces are reduced, nutrient transport does not occur thoroughly, causing microalgae cells to not undergo good cell division that affects the time of growth rate.

In $200 \mathrm{~mL}$ culture stock, we obtained faster growth rate so that it reaching stationary phase faster when compared with both other culture stocks, that is $150 \mathrm{~mL}$ and $250 \mathrm{~mL}$. This become indication that at amount of growth media $1 \mathrm{~L}$, using $200 \mathrm{~mL}$ microalga density, is the best to obtain a fast growth rate. The growth of $P$. cruentum microalgae was observed daily for 14 days of culture, to obtain the amount of $P$. cruentum density presented by growth graph in Figure 1.

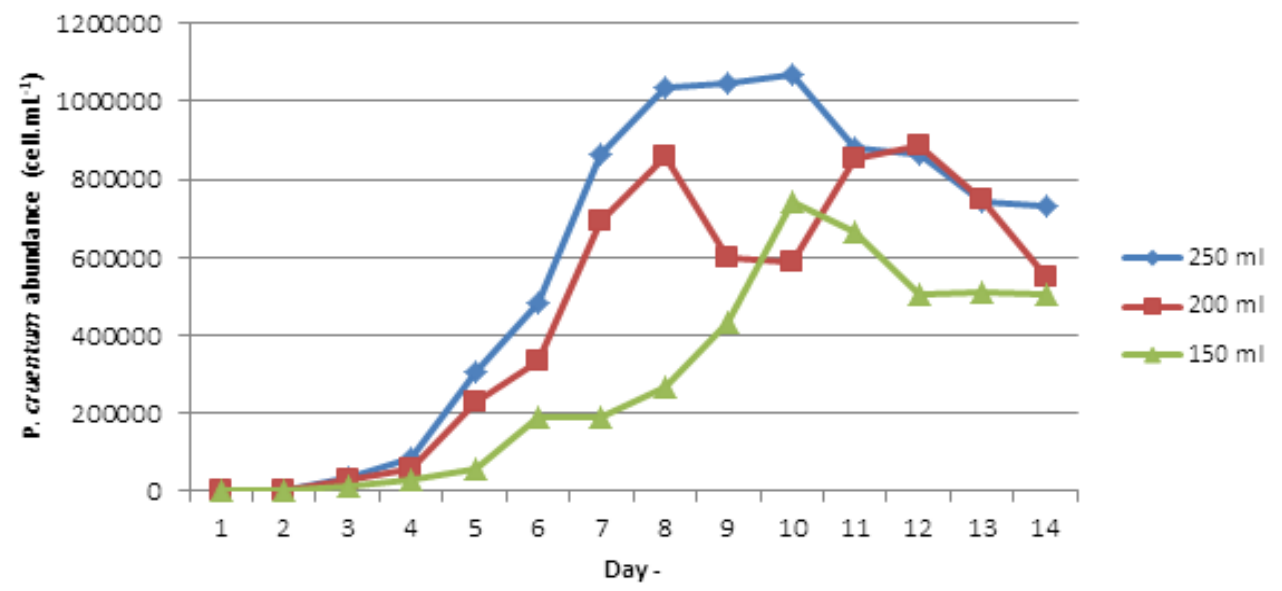

Figure 1. Porphyridium cruentum growth with $15 \%, 20 \%$ dan $25 \%$ culture stock density, with 2500 lux lighting and continuous aeration, for 14 days of culture.

\section{Extracellular Polysaccharide (EPS)}

The concentration of EPS was obtained by centrifugation process followed by the extraction process, used $96 \%$ ethanol solvent with media and solvent ratio of $1: 0.75 \mathrm{v} / \mathrm{v}$. Based on microalgae culture results for 14 days of rainy season, at $15 \%$ culture density obtained EPS + 10.000 mg. $\mathrm{L}^{-1}$ culture medium, $20 \%$ culture stock density obtained EPS $+12.000 \mathrm{mg} \cdot \mathrm{L}^{-1}$, and density stock culture $25 \%$ obtained EPS $+15.000 \mathrm{mg} . \mathrm{L}^{-1}$ (Table 1).

A culture of Porphyridium sp. was performed in winter and extracellular polysaccharide values are obtained from 200 to $1000 \mathrm{mg} . \mathrm{L}^{-1}$ [18]. In contrast to Setyaningsih et al. [13], where extracellular polysaccharide values were obtained from 12,500 - 21,500 mg. $\mathrm{L}^{-1}$ for a culture time of 12 days. Differences in extracellular polysaccharide values can be influenced by differences in the culture medium used, which include differences in the nutrient composition of each medium, in addition to differences in temperature and illumination

Table 1. Extracellular Polysaccharide Components (EPS)

\begin{tabular}{cc}
\hline P. cruentum Culture Stock $\left(\mathbf{m L}^{\mathbf{L}^{-1}}\right)$ & EPS $\left(\mathbf{m g}^{-\mathbf{L}^{-1}}\right)$ \\
\hline $\mathbf{1 5 0}$ & 10,000 \\
$\mathbf{2 0 0}$ & 12,000 \\
$\mathbf{2 5 0}$ & 15,000
\end{tabular}


Biologically extracellular polysaccharides function to protect microalgae cells, play a role in ion exchange or reservoir, as a barrier wall that is difficult to penetrate by gas and water. It is also serves as a place of excretion of vitamins and hormones [1]. The number of EPS obtained shows good microalgae growth, and good cell metabolic processes, to produce continuous extracellular compounds. The resulting extracellular polysaccharides will be a source of nutrients for cells in the growth process. The more cell division occurs, the EPS excretion process will increase, and can extend the growth phase of microalgae caused by the availability of nutrient reserves of EPS.

The chemical composition of EPS is identified from the expression of the functional group via the FTIR test. The graph in Figure 2 shows the chemical compounds read through the functional groups such as wavelength absorption 3442.769 indicating the presence of hydroxylate bond ($\mathrm{OH})$, wavelength absorption at 2239.846 indicates the presence of carboxylic acid bond (-
$\mathrm{COOH})$, the $\mathrm{CO}$ bond is indicated by a long absorption wave 1625.614, while wavelength absorption 1438.650 and 1362.350 indicate the presence of phenol bonds, as well as at $1200-800$ wavelength absorption indicates the presence of polysaccharide bonds.

Hasanah in 2016 performed FTIR test on P. cruentum EPS found that extracellular type of extracellular polysaccharide sugar was identified only maltoheptose composed of seven maltose disaccharides which is a component of glucose [10]. In contrast, Raposo et al. in 2014, found $P$. cruentum EPS was tested by GCMS (Gas Cromatografy Mass Spectrometry) method in which extracellular polysaccharides were identified to contain several major sugar components, including galactose (26.5-36.5 M\%), glucose (22.5-24\% M), and arabinose (16 M\%). While other sugar components such as mannose, fucose, xylose, and rhamnose were also detected with low concentrations of $11,9,7$ and $4 \mathrm{M} \%$ [14].

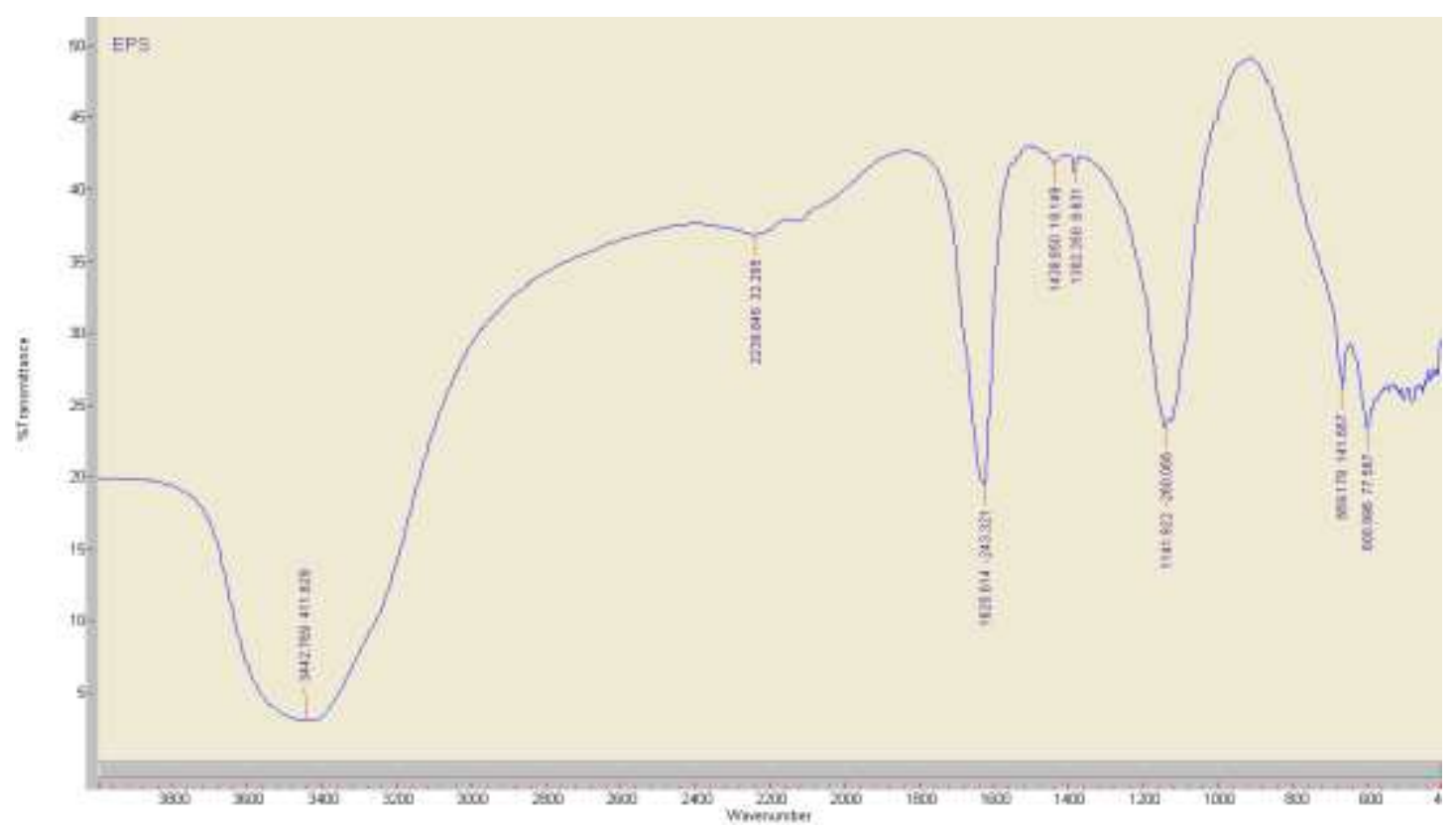

Figure 2. Extracellular polysaccharide functional group (EPS) Porphyridium cruentum, using FTIR test at $4000-500 \mathrm{~cm}^{-1}$ wavelength.

It was reported that EPS in $P$. cruentum composition with several different fractionation treatments using TLC (Thin-layer Chromatography) and GC measurements, so it was known that EPS content included Xyl, Glc, and Gal sugar [19]. Through the method of $m$-hydroxybiphenyl assay, sodium rhodizonate assay and IR spectrophotography, it was found that EPS sugar content included uronic acid and sulfate compound, through IR spectrophotography on band $820 \mathrm{~cm}^{-1}$ indicated hydroxyl primer sulfate group. This shows that the EPS extract contains sugar D- and L-Gal (Fig. 3).

Through a previous study of Geresh et al. in 1990 [20], it found $\alpha$-D-glucopyranosyluronic acid-( $1 \rightarrow 3)$-L-galactopyranose disaccharide from hydrolyzate acid Porphyridium sp. It indicates the configuration of each of GIcA and Gal are D- and - 
L. This disaccharide type is known as the polysaccharide constituent part for several types of red microalgae.

Differences in sugar composition in the EPS testing, allegedly caused by hydrolysis factors that have not been optimal, in this case may be the time of hydrolysis used has not been able to break the chemical bonds EPS Porphyridium cruentum so that no overall chemical composition EPS detected. The amount of galinisic acid hydrolyzed with $0.2 \mathrm{M} \mathrm{H} 2 \mathrm{SO} 4$ at $80^{\circ} \mathrm{C}$ reached $2.5 \%$ for 28 hours and at $100^{\circ} \mathrm{C}$ reached $6 \%$ for 16 hours $\mathrm{w} / \mathrm{w}$ [21]. It shows that hydrolysis values can be influenced by the time and temperature used. In addition Hasanah [10] confirmed the factors that can affect the hydrolysis level can be the time, temperature, type and concentration of the sample, and used solvent.
One of the ingredients that can be used as an immunostimulant is a polysaccharide compound [22]. Polysaccharides are a classification of carbohydrates which are a combination of monosaccharide molecules composed of over 6 molecules of monosaccharides, and they can be hydrolyzed back into many monosaccharide molecules. Polysaccharide compounds have the ability to stimulate the body's immune system [7]. EPS can also be $\beta$-mannan, $\beta$-glucan, xanthan, dextran, curdlan and gellan, which have many benefits in various fields such as stabilizers, emulgators, gelling or thickener, and possess the ability to bind water well so as to maintain texture remain soft during storage time in the food industry. On the other hand in the field of health EPS is able to show anti-tumor activity, and able to improve health through increased immune power and can lower cholesterol [23].

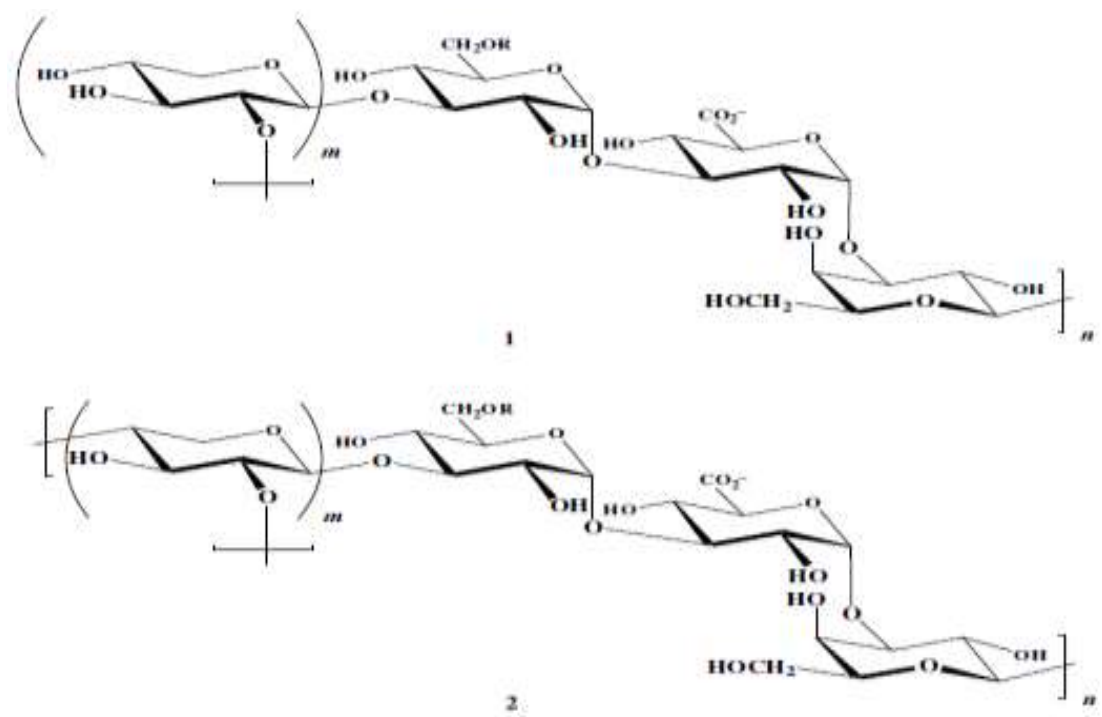

Figure 3. Unit Polysaccharide 1). Terminal Gal, 2). Xyl Terminal [19]

\section{CONCLUSION}

Variation of $P$. cruentum culture showed different EPS results, with a density of $25 \%$ capable of producing the highest EPS extract of $15,000 \mathrm{mg} \cdot \mathrm{L}^{-1}$. Increased chemical content of P. cruentum may be affected by culture modification by the addition of various fertilizers and vitamin supplements. The chemical composition of the dominant EPS is obtained by compounds of hydroxylate bonds including polysaccharides which can be utilized in the health and industrial fields.

\section{REFERENCES}

[1] Borowitzka, M.A., L.J. Borowitzka. 1988. Micro-algal biotechnology. Cambridge University Press. Cambridge.
[2] Kusmiyati, N.W.S. Agustini. 2007. Uji aktivitas antibakteri dari mikroalga $P$. cruentum. Jurnal Biodiversitas. 8(1). 48-53.

[3] Madigan, T.D., J.M. Martinko, J. Parker. 2009. Brock biology of microorganism, $12^{\text {th }}$ Ed. Pearson/Benjamin Cummings. San Francisco.

[4] Sharma, O.D. 1986. Textbook of algae. Tata Mc. Grow Hill Publishing Company Limitted. New Delhi.

[5] Garcia, I.R., J.L.G. Guerrero. 2008. Evaluation of the antioxidant activity of three microalgal species for use as dietary supplements and in the preservation of foods. Food Chem. 108(3). 1023-1026. 
[6] Kosasih, Y. 2011. Aktivitas komponen antibakteri aikroalga Porphyridium cruentum terhadap berbagai jenis bakteri patogen. Bachelor Thesis. Department of Aquatic Product Technology, Bogor Agricultural University. Bogor.

[7] Manilal A., S. Sujith, G.S. Kiran, J. Selvin, C. Shakir, R. Gandhimathi, A.P. Lipton. 2009. Antimicrobial potential and seasonality of red algae collected from the southwest coast of India tested against shrimp, human and phytopathogens. Ann. Microbiol. 59(2). 207-219.

[8] Fuentes, M.M.R., J.L.G. Sanchez, J.M.F. Sevilla, F.G.A. Fernandez, J.A.S. J.A.S. Pérez, E.M. Grima. 1999. Outdoor continous culture of Porphyridium cruentum in a tubular photobioreactor: quantitative analysis of the daily cyclic variation of culture parameters. Progress Ind. Micobiol. 35. 271-288.

[9] Fuentes, M.M.R., G.G.A., Fernandez, J.A.S. Perez, J.L.G. Guerrero. 2000. Biomass nutrient profiles of the microalga Porphyridium cruentum. Food Chem. 70. 345-353.

[10] Hasanah, 2016. Pemisahan biomassa dan eksopolisakarida Porphyridium cruentum menggunakan ultrafiltrasi serta pengaruhnya terhadap aktivitas inhibisi $\alpha$ Glukosidase. Master Thesis. Aquatic Product Technology Graduate School, Bogor Agricultural University. Bogor.

[11] Irwani, A. Ridlo, Widianingsih, 2013. Optimalisasi total lipid mikroalga Porphyridium cruentum melalui pembatasan nutrien dan fotoperiod. Buletin Oseanografi Marina. 2(2). 16-23.

[12] Rahman, D.A. 2011. Aktivitas antihiperglikemik dari biomassa dan polisakarida ekstraseluler Porphyridium cruentum sebagai Inhibitor $\alpha$-Glukosidase. Bachelor Thesis. Department of Aquatic Product Technology, Bogor Agricultural University. Bogor.

[13] Setyaningsih, I., E. Salamah, D.A. Rahman. 2013. Komposisi kimia dan aktivitas antihiperglikemik biomassa dan polisakarida ekstraseluler dari mikroalga Porphyridium cruentum. Jurnal Pengolahan Hasil Perikanan Indonesia. 16(1). 79-85.

[14] Raposo M.F., A.M. de Morais, R.M. de Morais. 2014. Influence of sulphate on the composition and bacterial and antiviral properties of the exopolysaccharide from
Porphyridium cruentum. Life Sci. 101(1-2). 56-63.

[15] Mishra, A., B. Jha. 2009. Isolation and characterization of extracellular polymeric substances from microalgae Dunaliella salina under salt stress. Bioresour. Technol. 100. 3382-3386.

[16] Dermoun, D., D. Chaumont, J.M. Thebault, A. Dauta. 1992. Modelling of growth of Porphyridium cruentum in connection with two interdependent factors: light and temperature. J. Bioresour. Technol. 42. 113117.

[17] Prayitno, J. 2015. Pola pertumbuhan dan pemanenan biomassa dalam fotobioreaktor mikroalga untuk penangkapan karbon. Jurnal Teknologi Lingkungan. 17(1). 45-52.

[18] Singh S., S.A. Arad, A. Richmond. 2000. Extracellular Polysaccharide production in outdoor mass cultures of Porphyridium sp. in Flat Plate Glass Reactors. J. Appl. Phycol. 12. 269-275.

[19] Geresh, S., S. Arad, O. Levy-Ontman, W. Zhang, Y. Tekoah, R. Glaser. 2009. Isolation and characterization of poly- and oligosaccharides from the red microalga Porphyridium sp. Carbohydr. Res. 344(3). 343-349.

[20] Geresh, S., O. Dubinsky, S. Arad, D. Christiaen, R. Glaser. 1990. Structure of 3-O(alpha-D-glucopyranosyluronic acid)-Lgalactopyranose, an aldobiouronic acid isolated from the polysaccharides of various unicellular red algae. Carbohydr. Res. 208. 301-305.

[21] Emaga, T.H., N. Rabetafika, C.S. Blecker, M. Paquot. 2012. Kinetics of the hydrolysis of polysaccharide galacturonic acid and neutral sugars chains from flaxseed mucilage. Biotechnol. Agron. Soc. Environ. 16 (2). 1-14.

[22] Sakai, M. 1999. Current research status of fish immunostimulan. Aquaculture. Faculty of Agriculture, Miyazaki University. Miyazaki.

[23] Yang, F., Y. Shi, J. Sheng, Q. Hu. 2006. In Vivo immunomodulatory activity of polysaccharides derived from Chlorella pyrenoidosa. Eur. Food Res. Technol. 224(2). 225-228. 